\title{
Pragmatic enrichment: Beyond Gricean rational reconstruction - A response to Mandy Simons
}

\author{
Robyn Carston \\ UCL Linguistics \& CSMN, Oslo
}

\section{Introduction: Simons' Gricean project}

Mandy Simons' main goal in her paper 'Local Pragmatics in a Gricean Framework' is to show that what are known as 'embedded pragmatic effects' are not a problem for Grice's programme of conversational logic, contrary to what has been widely assumed. More specifically, she sets out to show that elements of pragmatic meaning such as those noted below in italics for the following examples can be given explicit rational reconstructions of the reasoning by which they could be derived:

1. A: What will you do for your mother's birthday?

B: Either I'll buy flowers or I'll cook a nice dinner.

>> 'buy flowers' understood to mean: buy flowers and give them to my mother; 'cook a nice dinner' understood to mean: cook a nice dinner to share with my mother

2. A: What's making noise up in the attic?

B: I'm not sure, but if there's a nest up there, we're going to have a heck of a mess to clean up.

>> 'a nest' understood to mean: a nest occupied by birds

The key point about these components of pragmatic meaning is that they arise in embedded clauses, that is clauses which fall in the scope of logical operators, disjunction in (1) and the conditional in (2); similar examples could involve negation or a propositional attitude verb (e.g. 'John thinks there's a nest up there' in response to A's question in (2)).

Had the embedded clause been uttered alone, the pragmatically inferred meaning would be described as a Gricean conversational implicature:

3. B: I'll cook a nice dinner.

Implicature: The nice dinner I'll cook will be to share with my mother.

4. B: There's probably a nest up there.

Implicature: The nest is occupied by birds. 
Refreshingly, all of Simons' key examples are cases of what Grice would have explained as relevance-based implicatures rather than the quantity or scalar implicatures, which have come to dominate the literature; indeed, these examples are very similar to Grice's example 'There's a garage round the corner' (Grice 1975/89: 32) ${ }^{1}$, where the speaker, specifically observing the maxim 'Be relevant', conversationally implicates that the garage is open (and selling petrol). The sameness of the pragmatic contents derived for the embedded and unembedded cases has led to quite widespread talk of 'embedded implicatures' for cases like (1) and (2). This locution is, strictly speaking, a contradiction in terms, given Grice's clear characterisation of implicatures as non-truth-conditional components of utterance meaning, hence as not embeddable within the truth-conditional content ('what is said') of an utterance. Simons is faithful to Grice in this regard and does not employ this phrase but talks throughout of 'embedded pragmatic effects' or 'local pragmatic effects'.

In my view, Simons succeeds admirably in her goal of providing Gricean rational reconstructions of how these components of meaning could be recovered by hearers/ interpreters. Following her catch phrase 'think globally, act locally', she provides convincing accounts of (1) and (2) above which employ global Gricean reasoning, based on an assessment of the compositional semantic content of the sentences uttered, in deriving the local (embedded) pragmatic effects. Thus, in this short commentary, I do not take issue with the central point of her paper, but instead poke around the edges of the whole endeavour, suggesting it be extended and developed in certain ways and thereby made a bit more ambitious and (in my view) more interesting.

First, I'll raise some questions about the way in which the problem of 'embedded pragmatic effects' is construed within Grice's programme, based on his own expressed worries about this very phenomenon. I am not convinced that the real issue here is whether or not these pragmatic effects can be explained by the Gricean 'working out schema', as it seems to me that any and all pragmatic phenomena must be so explainable; rather, the issue lies with Grice's saying/implicating distinction, in particular his notion of 'what is said' and its essentially semantic nature. Second, I consider Simons' points that, given her successful rational reconstructions of how the components of pragmatic meaning at issue can be derived, there is both a local and a global view of the resulting contents, that is, they may either be taken to contribute to 'what is said' by the speaker (the proposition she has expressed, the truth-conditional content of her utterance) or be construed as conversational implicatures, and that it doesn't make much difference one way or the other. I think it does make a difference and the difference matters, and will suggest that the embedded (and other local) effects are components of a properly pragmatic notion of 'what is said', not of implicated propositions. Third, I maintain that it is time to move beyond normative rational reconstructions of the logic of speaker-hearer interactions, towards a more empirically cognitively based account of communication and the processes of pragmatic interpretation.

${ }^{1}$ Throughout this paper, all pages references to work by Grice refer to the versions (re)printed in Grice (1989). 
There is a lot more to 'local pragmatics' than 'embedded pragmatic effects' and there are several post-Gricean theories on the market nowadays which are pursuing accounts of these pragmatic phenomena which, arguably, move us closer to the cognitive mechanisms actually employed in utterance comprehension.

\section{The issue for the Gricean programme}

To put my view simply and baldly: the problem that embedded pragmatic effects pose for the Gricean model is not their reconstructibility by a reasoned argument of the sort Grice provides in his 'working out schema', but concerns how they can be accommodated by his particular view of the saying/implicating distinction, in particular, his concern to keep 'what is said' as close as possible to the conventional linguistic meaning of the sentence uttered. That is what I will try to argue for in what follows, first by looking at Grice's own statements about these embedded cases, second by briefly examining the way in which the Gricean project was temporarily derailed by formal treatments of the phenomenon of scalar implicatures, and third by unpacking his problematic concept of 'what is said', which, as it stands, is not easily reconciled with embedded pragmatic effects, as he acknowledged.

\subsection{Grice's worry: the scope of conversational implicata}

The problem that the original Cohen (1971) examples made for Grice concerned his truthfunctional semantics for natural language connectives such as 'and' and 'if'. Cohen maintained that Grice's 'conversationalist hypothesis' regarding the frequent non-truthfunctional meaning of 'and' had to give way to Cohen's 'semantical hypothesis', because the sequential and consequential relations between the first and second conjuncts in examples like (5a) and (5b) clearly affect the truth-conditional content of the conditionals and thus the truth value of the statements made by asserting them:

5. a. If the old king died of a heart attack and a republic was declared, Tom will be happy.

b. If a republic was declared and the old king died of a heart attack, Tom will be happy.

Cohen makes no mention of there being any problem concerning the possibility of giving a Gricean rational reconstruction of the enriched content. His argument against the conversationalist hypothesis turns entirely on the impossibility of maintaining a truthfunctional semantics for both 'if' and 'and' if implicated meaning is allowed to enter into the truth evaluation of (5a) and (5b), in that one or other (or both) of them would no longer be operating solely on the truth values of their clausal subparts. 
As far as I am aware, Grice never attempted any head-on rebuttal of Cohen on this point and had, in fact, already expressed his own disquiet about a parallel problem arising for denials of some ordinary language conditionals, such as the example in (6), where it seems that, given the standard truth-functional account of 'if' (as equivalent to the material conditional), what the speaker denies is an implicature of the utterance of the unnegated conditional:

6. It is not the case that if $\mathrm{X}$ is given penicillin, he will get better.

Commenting on this sort of example, Grice said: “... if the affirmation of "if $p$, q" carries an implicature, its denial has to be interpreted as the denial of the implicature. This principle does not appear to be acceptable.' (Grice 1967/89: 83). Later in his 'Retrospective Epilogue' (1987/89), when he looks back on his account of the 'vulgar logical connectives', he does not seem to have got much further with finding an answer to the vexing question 'whether it is or is not required that a nonconventional implicature should always possess maximal scope'. He allows that there are some cases where negation has to be taken as a denial of the implicature of the embedded sentence/utterance, specifically, cases of metaphor where the literal content is absurd (e.g. 'She is not the cream in my coffee'), but ends by saying: 'But where the limits of a license may lie which allows us to relate embedding operators to the standard implicata rather than to conventional meanings, I have to admit that I do not know.' (Grice 1987/89: 375).

Both Grice and Cohen envisaged only two possibilities for explaining the enriched (non-truth-functional) meaning of the connection between conjuncts or between antecedent and consequent of a conditional: either it was a matter of conversational implicature or a matter of the (lexical) semantics of the connectives 'and' and 'if' (whether an ambiguity analysis, with the truth-functional meaning being just one of the conventional senses, or a single rich meaning, with contextual cancellation of certain of its components, as Cohen advocated). Neither Grice nor Cohen considered the possibility of a third kind of account, viz. a local pragmatic enrichment of the connection between propositional subparts of the utterance, while maintaining the truth-functional semantics of the connectives themselves. This was simply inconceivable, given the way in which the semantics/pragmatics (= saying/ implicating) distinction was construed at the time. Even now, after various reconstruals of the distinction, including differentiating 'what is said' from sentence semantics, the phenomenon at issue is still widely talked of negatively, as 'pragmatic intrusion' into what is said (the truth-conditional content of the utterance).

What I want to emphasise at this point is that there is no evidence that Grice's worry about cases of implicature apparently falling in the scope of logical operators was a worry about their derivability, their susceptibility to being explained by a line of rational reconstructive reasoning involving his conversational maxims. In fact, if we take seriously Grice's emphasis on the distinction between conventional and non-conventional components 
of utterance meaning, there is no obvious reason not to extend his general pattern of reasoning to other nonconventional (pragmatic) components of utterance meaning, including cases that clearly contribute to 'what is said', such as ascertaining the referents of demonstratives and indexicals, selecting the sense of ambiguous words, and (perhaps) completing apparent cases of nonpropositional sentence content (e.g. for utterances of 'He is ready', 'She's too tall', etc.). It was pointed out long ago that Grice's maxims apply to these too (e.g. by Katz (1972: 449) and Walker (1975: 156-7)), and, more recently, by Stalnaker (1989: 9): 'the Gricean principles and maxims clearly play a role in resolving ambiguity and fixing contextual parameters as well as in generating conversational implicatures'. Some current Gricean pragmaticists provide explicit rational reconstructions of such phenomena; for instance, Geurts \& Rubio-Fernandez (2015: 2) set out the following line of Gricean reconstructive reasoning for the disambiguation of the word 'chestnut' in the comprehension of an utterance of the sentence 'The chestnuts are shedding their leaves': '(a) She has used the word "chestnut"; (b) there is no reason to suppose that she is not observing the Cooperative Principle; (c) she could not be doing this unless she intended to refer to trees of the genus Castanea, for this is one of the standard meanings of the word, and it fits our discourse purpose better than any of the others; (d) she knows (and knows that I know that she knows) that I can see that the supposition that she intends the word in this meaning is required; (e) she has done nothing to stop me thinking that this is so; (f) she intends me to think, or is at least willing to allow me to think, that she intended to refer to this type of tree; (f) and so this is what she has implied.' Now, clearly, the nature of the input to the reasoning (the premise in (a)) and the nature of the output (a word meaning) differ from the input (what is said) and the output (a conversational implicature) of Grice's schema, but the actual pattern of reasoning is virtually identical (see Grice 1975/89: 31).

Simons might object to this sort of account of disambiguation as not properly Gricean because it doesn't start from the global consideration of the cooperativity of a complete speech act (what is said). Along with Geurts \& Rubio-Fernandez, I don't see that this makes the actual line of reasoning non-Gricean and, in any case, something of the sort she requires can be pretty easily supplied as the initial input to the rational reconstruction, given that this need not bear any close relation to the actual psychological processes of addressees: '(a) The speaker has said one of the following three things: (i) that the chestnut trees are shedding their leaves, (ii) that the nuts from the chestnut trees are shedding their leaves, (iii) that the chestnut horses are shedding their leaves; (b) there is no reason to suppose that she is not observing the Cooperative Principle; and so on (as above).' Furthermore, although Simons emphatically maintains that her Gricean accounts of the embedded pragmatic effects in (1) and (2) above are achieved without what she calls 'embedded pragmatic computation', it is not so clear that this really is the case. According to her definition, an embedded pragmatic computation involves general pragmatic principles operating on 'the content of an unasserted embedded clause; or the observation that the speaker has expressed this content; ...' (p.5). In her account of the pragmatic enrichment of 
'buy flowers' to buy flowers to give to mother for her birthday in (1), the disjunct 'I'll buy flowers' is found to be insufficiently relevant (not adequate as a potential answer to the question asked) and the pragmatic enrichment is performed so as to make it sufficiently relevant. ${ }^{2}$ Her idea is that what kicks off the Gricean reasoning is the recognition that the compositionally derived content of the disjunction as a whole is not sufficiently relevant and (then) the hearer recognises that the problem lies with the first disjunct (and, presumably, also the second disjunct). However, nothing precludes it being the case that it is the recognition of the 'failure of relevance of the first disjunct', as she puts it (p.11), that triggers the Gricean reasoning in the first place.

Be that as it may, I see no problem at all with the application of pragmatic principles, Gricean or otherwise, to unasserted utterance parts, in the interests of recovering the intended interpretation of the utterance as a whole (as suggested way back by Walker 1975). The overriding point here is that it is inherent to pragmatic phenomena (as opposed to those that are a matter of linguistic convention or encoding) that they are derived inferentially and that, 'even if they can be intuitively grasped, unless the intuition is replaceable by an argument, the meaning will not count as pragmatic; it will be conventional/encoded' - here, I am echoing Grice's own statement about 'conversational implicature' versus 'conventional implicature'. ${ }^{3}$ So why has the idea caught on that there is a major problem with providing Gricean reconstructions of embedded or local pragmatic content? The answer, I think, lies, in part at least, with the way in which accounts of a particular kind of pragmatic inference, known as 'scalar implicature', have evolved.

\subsection{Scalar implicatures and formal rules of derivation}

Much has been made in the vast literature on 'scalar implicature' of the difficulties of giving a Gricean account of the derivation of this kind of generalised quantity-based pragmatic inference when it occurs in embedded clauses. Simons mentions the example in (7) and another much discussed sort of example is that given in (8); in both cases, the desired pragmatic interpretation is the one given after $>>$, and the claim has been that Gricean

\footnotetext{
${ }^{2}$ In Simons (2010), she says quite explicitly that what she is doing is departing from Grice in that, rather than seeing implicatures as arising from observations about what the speaker has said, 'we should instead see conversational implicatures as inferences generated by observations about what a speaker has (merely) expressed: this includes observations about sentence parts whose content is not part of what is asserted ...' (ibid: 163). The sentence parts at issue in that paper are exactly the same as those at issue in the current paper, i.e. disjuncts and antecedents of conditionals. Perhaps what Simons takes herself to be doing in the current paper is going back on her departure in the 2010 paper, as having found a way to be more faithfully Gricean, but she doesn't say this explicitly (in fact, she doesn't refer at all to the 2010 paper, although it seems to be very much a precursor to the current one) and, as far as I can see, pragmatic principles (specifically, the maxim of relevance) are being applied to unasserted sentence parts here too.

3 'The presence of a conversational implicature must be capable of being worked out; for even if it can in fact be intuitively grasped, unless the intuition is replaceable by an argument, the implicature (if present at all) will not count as a conversational implicature; it will be a conventional implicature' (Grice 1975/89: 31).
} 
reasoning does not deliver it, but rather only the too weak inference in (7) and the too strong inference in (8), as indicated after \#\#:

7. Prof Smith believes that some of her students are in her office.

>> Prof Smith believes that some but not all of her students are in her office.

\#\# It's not the case that Prof Smith believes that all of her students are in her office.

8. Either Kai ate the broccoli or he ate some of the peas.

> Either Kai ate the broccoli or he ate some but not all of the peas.

\#\# It's not the case that either Kai ate the broccoli or he ate all of the peas.

Hence: Kai didn't eat the broccoli and he didn't eat all of the peas.

What seems to have happened is that the phenomenon of quantity/scalar implicatures got reduced to a few cases of scalar terms ('some', 'often', 'or', and the number terms) which occupy a position on an entailment scale (e.g. <some, most, all>) and for which a simple automatic derivational procedure was proposed. Grounded in Grice's first maxim of Quantity, but making no explicit reference to it, the procedure is as follows: 'For every $\alpha$ higher on the entailment scale in which the uttered scalar term $\beta$ occurs, infer, as an implicature, that the speaker believes/knows that the $\alpha$ counterpart of the uttered sentence is false.' So, for the sentence/utterance 'Some of the kids are sick', the procedure generates the implicature 'The speaker knows/believes that it is not the case that all of the kids are sick' and then, assuming speaker reliability, the standard scalar implicature follows: 'Not all of the kids are sick'. The instigator of this approach was Gazdar (1979: 57-61), but it has been taken up in variant forms by many others (e.g. Gamut 1991; Levinson 1983, 2000).

It turns out that this fixed procedure often doesn't work when the scalar term (e.g. 'some', 'often', 'four', 'or') occurs in an embedded clause, as in (7) and (8) above. ${ }^{4}$ But this, I would maintain, is a problem with the rigid scalar inference procedure and not with the Gricean reasoning schema, which provides a very general and flexible method for calculating conversational implicatures of all sorts (and, as suggested above, for calculating other kinds of pragmatic phenomena too). This has now been demonstrated by, among others, Geurts (2010), who provides Gricean style inferential derivations for the seemingly problematic cases, in which the first maxim of Quantity plays a central role.

I don't mean to underestimate the complexity of figuring out the key premises needed in providing a rational reconstruction of the pragmatic inferences involved in arriving at the intuitively correct interpretation of cases like (7) and (8). This is indeed tricky, as the reconstruction requires reasoning about the relevant stronger statements the speaker could

\footnotetext{
${ }^{4}$ It should be noted that Gazdar (1979) explicitly excluded occurrences of scalar terms in the scope of logical operators from his procedure, but, as others subsequently pointed out, such cases do give rise to implicatures of a scalar sort, just not the ones that the procedure would generate (see Hirschberg 1985, Recanati 2003, Sauerland 2004 on problems with extending Gazdar's procedure to cover these cases). There are other issues with Gazdar's procedure and it has been much tinkered with over the years, but the details don't matter here.
} 
have made and assessments of her epistemic competence with regard to the facts of the situation under discussion. For instance, the reasoning that leads to the interpretation of (8) as Kai either ate the broccoli or some but not all of the peas involves consideration of four relevant alternative stronger utterances and of what the speaker can be reasonably supposed to believe about their truth/falsity given the utterance she chose to produce (see Geurts 2010: 166-68). ${ }^{5}$ However, the initial recognition that some further component of speaker meaning is required to preserve the presumption that the speaker is being cooperative (which Simons calls the step of Gricean reasoning) is entirely standard, and it is at the second stage (which she calls the interpretive step) that the theorist (the rational reconstructor) needs to exercise some ingenuity in providing the right premises.

My main point here is that it is the lengthy debate occasioned by these cases and their assumed automatized derivational procedure ${ }^{6}$ which has promoted the perception that there is something amiss with the Gricean mechanism when it comes to providing a reasoned argument for the presence of what seems to be embedded pragmatic material. But this is wrong: the apparent problem arose because the formal procedure, which generated the right implicature for utterances of stand-alone clauses containing scalar terms, generated an array of erroneous results when that clause occurs embedded in the scope of an operator. This is simply not a problem if we drop the procedure and go back to Grice's informal and very general reasoning schema. Furthermore, problems posed by a formal procedure of the sort set up for quantity-based scalar implicatures do not arise for the cases discussed in detail by Simons: she focuses on relevance-based pragmatic inferences and they are 'particularized' (context-specific) cases, so there is no temptation to see them as default inferences or routinized in any way. In his book in which he makes the case for default-rule accounts of a number of implicatures, in particular the scalar cases, Levinson (2000) does not try to extend this to such relevance-based cases, but instead invokes a very general 'Enrichment Rule' for hearers to follow: 'Amplify the informational content of the speaker's utterance by finding the most specific interpretation, up to what you judge to be the speaker's m-intended point, ...' (ibid: 114). Although this seems right, it is no more than a general guideline and Simons does us a service by providing explicit step-by-step demonstrations of how these contextspecific amplifications can be derived by Gricean style reasoning employing the $\mathrm{CP}$ and

\footnotetext{
${ }^{5}$ Note that the result of Geurts' account is the implicature 'Kai didn't eat all of the peas'. Putting that together with 'what is said', the overall interpretation can be paraphrased as 'Kai either ate the broccoli or he ate some but not all of the peas'. His account, although very Gricean as compared with the grammatical/lexical accounts he is rejecting, still seems somewhat in the grip of the Gazdarian formal procedure approach. In this regard, I think Simons account of disjunctions is better, in that it enables quantity-based reasoning on the second disjunct resulting in the (intuitively correct) embedded enrichment 'some but not all of the peas'.

6 There was a downward spiral, starting with the semi-formal procedure introduced by Gazdar (1979), to the default implicature account of Levinson (2000), where the key inferences were seen as generated by defeasible rules attached to specific lexical items, including 'some', 'often', and 'or' (so inevitably derived and accepted unless contextually cancelled), through to the full-blown grammatical accounts of Chierchia (2004) and others.
} 
maxim of relation, but, as far as I can see, there was never any reason to doubt the feasibility of this. ${ }^{7}$

Finally, returning to the passages where Grice discusses his worry about whether an embedding operator may sometimes have to be taken as governing a nonconventional (conversational) implicature (1967/89: 83 and 1987/89: 375), it's worth noting again that he maintained that for denials of metaphorical cases it is the implicature that is denied, not the absurd literal content:

9. Rex: She is not the cream in my coffee.

Rex denies that the female referred to is his pride and joy.

10. Alf: I spent the summer cleaning the Augean stables.

Babs: No, you didn't. (You spent two months lazing at the seaside.)

Babs denies that Alf spent his summer working on a difficult and long overdue task.

The embedding operator here is negation but the point would presumably carry over to the conditional too:

11. If she's the cream in his coffee, he's bound to give in to her demands.

If Mary can locate those old photos for him, she'll be the cream in his coffee.

At no point is it an issue for Grice whether or not the 'embedded implicature' is calculable by use of his standard reasoning schema; he simply assumes it is. What concerns him is the question of how to delimit the range of cases for which we must allow embedding operators to apply to 'the standard implicata rather than to conventional meaning'. I doubt that the Gricean framework can provide an answer to this question, given its very general (relatively unconstrained) reconstructive reasoning schema, on the one hand, and its overly constrained notion of 'what is said', on the other hand. An answer may, however, be found once we move to a more cognitively oriented account of pragmatic interpretation, as I suggest in section 4 below.

\section{3 'Globalism', what is said, and the move to 'making as if to say'}

Having shown that the pragmatic enrichments of 'buy flowers', 'cook a nice dinner' and 'nest', which occur within sub-clauses of the sentences uttered in (1) and (2) above, can be

\footnotetext{
7 Simons claims that relevance theorists 'are of the opinion that embedded pragmatic effects pose a challenge to the Gricean model of pragmatics. They take the Gricean model to be unable to account for the effects seen in Cohen's examples and others [with embedded pragmatic effects],' (p.2). As a relevance theorist, my issue is not with the ability of the Gricean reasoning schema to provide an account of how these effects might be derived, but rather with how they can be accommodated in Grice's 'model' given his particular construal of the saying/implicating distinction (Carston 2002, 2004; Carston \& Hall 2012).
} 
accounted for by pretty standard Gricean normative reasoning, Simons points out that the resulting propositional content can be construed either as what the speaker said (so the enrichment is truly local) or as a conversational implicature independent of what is said (hence as a wholly global inference). She doubts that there is any empirical evidence that could decide between the two construals and thinks that the preference is theory-driven, essentially dependent on one's construal of 'what is said'. Even if this is right, still one theory might be better than another and, on that basis, provide a reason for adopting one construal rather than the other. As discussed below in section 4, I believe that we can and should be moving beyond philosophers' rational reconstructions to accounts of pragmatics that come closer to the cognitive goals/constraints that direct actual processes of interpretation. This is what the relevance-theoretic account sets out to achieve and its cognitively constrained pragmatic processes deliver a localist implementation of the pragmatic effects under discussion.

However, staying for the moment within the Gricean framework, let's consider a line of defence that Simons adopts on behalf of the 'staunch globalist', who eschews 'pragmatic intrusion' into truth-conditional content. She suggests the availability of a move that I think really ought to be avoided. The globalist position would have it that B's utterance in (2), repeated here as (12), results in the contents as given in (13):

12. A: What's making noise up in the attic?

B: I'm not sure, but if there's a nest up there, we're going to have a big mess to clean up.

13. What is said: If there's a nest up there, we're going to have a big mess to clean up. What is implicated: If there's a nest occupied by birds up there we're going to have a big mess to clean up. ${ }^{8}$

The semantically generated 'what is said' seems not to fall within the speaker's meaning (it's not the case that just any old nest, e.g. a disused one, will produce a big mess), so Simons' suggested move for the globalist here is to 'avail herself of Grice's notion of making as if to say' (p.18) and to proceed from there to use standard Gricean reasoning to derive the conversational implicature, which constitutes the speaker's meaning. ${ }^{9}$ This does not seem to me to be a legitimate Gricean move. As noted earlier, this example, like all of Simons' cases, is an instance of particularised relevance-based Gricean reasoning and, along with Grice's example 'There's a garage round the corner', it falls into his Group A, 'Examples in which

\footnotetext{
8 The referents of 'we' and 'there' would have been provided, but this doesn't affect the point I want to make here about the relationship between the said and the implicated.

${ }^{9}$ I think the perceived need for such a move will arise whenever the embedding operator results in a downward entailing environment (e.g. negation) because the banning of any local pragmatic enrichment makes for a propositional content that is too broad to be speaker meant (e.g. 'not a nest' vs 'not an occupied nest').
} 
no maxim is violated, or at least it is not clear that any maxim is violated'. These are distinguished from his Group C, 'Examples that involve exploitation, that is, a procedure by which a maxim is flouted for the purpose of getting in a conversational implicature by means of something of the nature of a figure of speech.' (Grice 1975/89: 32-33) It is examples in this latter group, which includes cases of metaphor, hyperbole, meiosis, and irony, that prompt the move to 'making as if to say' and all involve a blatant overt violation of a maxim. This is not what is going on in Simons' example; although the literal linguistic meaning here happens to be false, this is just a function of the particular embedding operator and not a matter of a speaker blatantly flouting truthfulness or any other maxim. ${ }^{10} \mathrm{Had} \mathrm{B}$ in (12) responded to A with a different embedding operator, e.g. 'Either there's a nest up there or some squirrels have moved in', or with no embedding, e.g. 'Oh, there's a nest up there', the literal linguistic meaning would be entailed by the (alleged) implicature, hence part of what is speaker meant, and there would be no talk of 'making as if to say' or maxim flouting. This seems unsatisfactory in a different way, in that the 'said and meant' content is essentially an idle wheel as it is subsumed and expanded upon in what is (allegedly) implicated. Even if this latter concern may be deemed an innocuous redundancy, the bigger point here can't be so easily dismissed. There are no principled (or empirical) grounds for splitting this set of cases, all of which, as Simons herself assumes, involve relevance-based enrichment, into two quite different kinds: the 'making as if to say'/maxim-flouting cases and the 'genuine saying'/maxim-observing cases. If this is the only way to salvage globalism, then it looks as if localism is the preferable option.

To recap, the problem Simons' examples present for the Gricean framework is not, as she convincingly shows, their calculability, but how they are to be accommodated by his saying/implicating distinction, specifically, his conception of what is said. I've argued at considerable length elsewhere that Grice packs two incompatible constraints into this single concept: (a) the (pragmatic) requirement to be speaker meant, and (b) the (semantic) requirement to be as close as possible to the conventional compositional meaning of the sentence (Carston 2002, 2004; Carston \& Hall 2012). Different theorists deal with this problem in different ways, but what they tend to have in common is the separating out of these two requirements into different levels of analysis, that is, the semantic content of a sentence (even relative to a context) is one kind of thing, while the propositional content that is meant (communicatively intended) by the speaker is another. It is clearly the latter that is Simons' focus here and the issues now are: (a) whether or not there is a distinction to be made, within speaker meaning, between globally derived conversational implicatures and a propositional content which is, in effect, the outcome of local pragmatic enrichment of the conventional/encoded meaning of the sentence uttered; and, if there is, (b) whether there is

\footnotetext{
10 The one example Grice gives in Group C which involves a 'real, as distinct from apparent, violation of the maxim of Relation', something he considers quite rare, is the bland statement by B about the weather which follows A's statement 'Mrs X is an old bag' (Grice 1975/89: 35). This is a blatant refusal by B to make what he says relevant to A's preceding remark. Nothing like this is going on in Simons' examples.
} 
any reason to prefer one or the other of these as the locus of her cases of relevance-based pragmatic enrichment.

In the next section, I argue that there is a great deal more to local pragmatic effects than embedded pragmatic effects, in that the concepts (or senses) that speakers communicate with the words they utter are usually at least partially pragmatically derived. I believe that this goes quite a long way toward providing Simons with the kind of evidence she feels is lacking for choosing between the localist (what is said) construal of her pragmatic enrichment cases and the globalist (implicature) construal.

\section{Local pragmatics, the dynamic lexicon and 'what is said'}

Simons focuses on 'embedded' pragmatic effects, that is, components of pragmatically derived meaning which arise within clauses/propositions that fall in the scope of logical operators. In this section, I start by looking at the local pragmatics of utterances of simple sentences (no embedded clauses or logical operators). This goes well beyond the standard cases of ascertaining the intended referent of indexicals and the intended sense of ambiguous lexical/phrasal forms (e.g. 'bank', 'in the grip of a vice') and is essential to many (perhaps most) instances of grasping the meaning a speaker intends in uttering a word or phrase. The strategy is to first demonstrate the prevalence of local pragmatic adjustments in figuring out what the speaker said and, given this, to argue that there is no reason not to allow the exact same kinds of local adjustments in figuring out what the speaker said in uttering a more complex sentence containing an embedded clause.

Let's consider some cases of utterances of simple sentences. First, some examples adapted from Nunberg (1979):

14. a. He can hit the ball two football fields.

b. He hit a home run two games ago.

c. $\quad I B M$ went up three points last week.

What is expressed by this use of 'football field' is 'length of a football field'; 'game' is used to express a measure of time; 'IBM' is used to refer to 'IBM stocks'. Given their linguistic contexts here, there is no difficulty in seeing how these meanings can be pragmatically derived from the more well-established meaning of the word or phrase in each case (see Geurts 2010: 184, for a step-by-step Gricean derivation of the occasion-specific sense of 'football field' in (14a)). Next, consider some cases of novel 'denominal verbs', as discussed by Clark \& Clark (1979):

15. a. The boy porched the newspaper.

b. She wristed the ball over the net. 

c. He houdinied his way out of the closet.
d. The police car sirened up to the accident site.
e. Mum will jam-spoon you when she gets home.

Having run a series of experiments on people's ability to understand these, Clark \& Clark (1979: 767) concluded: 'people readily create and understand denominal verbs they have never heard before"11 (and no doubt the same goes for deverbal nouns, e.g. 'buy some nice eats', 'an embed in Iraq', 'a good get', etc.). The examples in (14) and (15) are all cases of verbal innovation (novel uses of existing words in (14) and new, but motivated, word coinages in (15)), whose meaning is inferred pragmatically, using as key evidence the existing known senses of the words on which they are based. The new communicated senses cannot but contribute to what the speaker said (the truth-conditional content of her utterance) or else she would have to be deemed, highly implausibly, to have not said anything at all, nor even made as if to say something, given that there is nothing propositional without this contribution. Whatever implicatures these utterances may have depend on there being some fully propositional component (what was said) on the basis of which, together with other premises, including the presumption that Gricean maxims are being observed, they can be inferred.

According to the relevance-theoretic approach to 'lexical pragmatics', interpreting a word (or phrase) frequently involves the construction of an ad hoc concept or occasionspecific sense, based on an interaction between linguistically encoded concepts, contextual information and pragmatic principles (see Wilson \& Carston 2007). The constructed sense may be a narrowing or a broadening of the encoded sense, or a combination of both. Here is a possible example of each:

16. a. I'm not drinking tonight.

b. If the kids go on this way, we'll be bankrupted.

c. Either she's a saint or he's a lot nicer to her at home.

A likely interpretation of 'drinking' in (16a) is a narrowing to 'drinking alcohol' and this may be further modulated on the basis of contextual knowledge to 'not drinking much alcohol' or 'not drinking spirits', etc. Taking (16b) as uttered by an exasperated parent whose children are constantly demanding new clothes and gadgets, she most likely doesn't intend 'bankrupted' strictly literally but is expressing a broader concept along the lines of 'made considerably poorer'. And (16c), a kind of metaphorical use, probably communicates a concept which is both broader and narrower than the literal meaning. ${ }^{12}$ The general point

\footnotetext{
${ }^{11}$ Of course, some need more context than others; (15e), which is my example, was used to express the proposition that Mum will beat the addressee with the (big wooden) spoon she uses for making jam when she gets home.

12 Some of the earliest work on 'local' or 'lexical/phrasal' pragmatics was by Jerry Hobbs and colleagues (e.g. Hobbs \& Martin 1987; for an overview, see Hobbs 2004). They focused, in particular, on cases of metonymy
} 
here is that our lexical resources do not consist of a static store of words and their meanings: we are constructing new senses (even new words) much of the time, some of which are oneoff, others of which become routinised to varying degrees, and a few of which take on the status of established word senses.

Polysemy is the phenomenon of a word having a number of related senses, but unlike cases of arbitrary ambiguity, known as 'homonymy' (e.g. 'bank', 'coach'), polysemy is highly variable across individuals apparently speaking the 'same language'; what is a case of semantic polysemy for you may be monosemy for me, requiring me to pragmatically infer the other sense(s), and vice versa for other cases. For instance, as a result of frequent use of the pragmatically derived sense, some English speakers may represent the words 'drink' or 'saint' as having two senses, while, for others who have encountered the derived use less often or not at all, the word may have only a single sense and the interpretation of the derived use would involve constructing (or reconstructing) an appropriate ad hoc concept. What this indicates, again, is that the lexical pragmatic processes responsible for concept construction are contributing to the truth-conditional content (what is said/asserted) of the utterance rather than merely affecting implicatures. It would be highly implausible to suppose that (16a) or (16c) would be understood as expressing or asserting different propositions depending on whether the intended sense of 'drinking' or 'saint' is recovered by disambiguation or by ad hoc concept construction. As we put it in Wilson \& Carston (2007: 241): 'One of the most important functions of pragmatic inference is to compensate for grammatical and lexical differences among members of a speech community, so that addressees with different encoded senses can end up with the same interpretations, albeit via different routes. 13

Note that each of the examples in (16) is an instance of an 'embedded pragmatic effect', in that each occurs within a clause that falls in the scope of a logical operator. Simons' staunch globalist would presumably require that the intended sense in such cases occurs as an implicature and that each of these utterances is a case of 'making as if to say'. But, following Grice, the globalist would take disambiguation (sense selection) as essential in reaching a full identification of what the speaker has said ('drink-1' or 'drink-2', 'saint-1' or 'saint-2'). So sticking staunchly to globalism entails that for some addressees of (16a) the speaker has said that she is not drinking alcohol tonight, while for others she has made as if to say that she is not drinking anything at all tonight and implicated that she is not drinking alcohol. This is an absurd outcome and not one, I believe, that Simons would want to ascribe to.

and noun-noun compounds, which are pretty much universally accepted as cases of meaning that contributes to the truth-conditional content of an utterance (what is said), thus as pragmatic contributions to (or 'intrusions' on) that content.

${ }^{13}$ I am less comfortable now with this talk of words having 'encoded senses' and suspect that grasping the senses expressed by speakers is essentially always a matter of occasion-specific concept formation, but with the accessibility of those senses/concepts varying across individuals, a matter which is dependent on their particular communicative experiences. The nature of standing word meaning is currently a much debated issue; for an overview of the possibilities, see Recanati (2004). 
Geurts (2010) makes similar points to mine about the pragmatic determining of speakers' word meanings: 'The dynamics of this process is Gricean: the logic that underwrites the selection and construction of word meanings is similar to that of conversational implicatures' (ibid: 184). Cases of scalar inferences that he accommodates in this way include the following:

17. a. Around here, we don't LIKE coffee, we LOVE it.

b. I'd rather have a WARM bath than a HOT one.

Taken strictly literally, (17a) would be a contradiction but the lexical meaning of 'like' is pragmatically narrowed to 'like but not love' and the proposition expressed (what is said) is thus a contingent truth; essentially the same goes for 'warm' in (17b). Here, as he clearly argues, Gricean reasoning is employed in establishing the truth-conditional meaning of the utterance, or 'what is said' (acknowledging that Grice's construal of 'what is said' has to be amended). He concludes: 'interpretation processes are guided by the Cooperative Principle from the lexical level up' (ibid: 85 ). ${ }^{14}$

Towards the end of her paper, Simons discusses the local pragmatic process of assigning a referent to an indexical, using the example of an utterance of 'He is late', for which 'all that the semantics gives to the interpreter' is an 'underspecified representation'. In such cases, 'The interpreter need not wait to identify what is said before she can pose ... the Gricean question' (p.24). Her assumption seems to be that it is only when the meaning delivered linguistically falls short of determining a proposition that pragmatic inference (Gricean reasoning) comes into play: 'In cases where the words uttered by the speaker do not determine a proposition, the reasoning begins from whatever semantic content or structure those words make available' (p.25). On this basis, her examples (1) and (2) would not involve local pragmatic enrichments of 'nest', 'buy flowers', etc., because, arguably, a proposition is determined without the need for these pragmatic enrichments. The criterion seems to be: 'if and only if nothing propositional is delivered by linguistic semantics, do whatever pragmatics is needed to make it propositional'. If this were applied to the lexical/phrasal cases discussed in this section, some of them would require local pragmatic work (e.g. the word coinages in (15)) and some would not (e.g. the meaning shifts in (14) and (16), although the proposition (allegedly) expressed/said in each of these cases is nonsensical), and this will vary from hearer to hearer depending on their lexicons, which, in turn, depend on their individual communicative histories. As far as I can see, there is nothing principled or warranted in this criterion and all of these should be treated in the same way, as

\footnotetext{
${ }^{14}$ In fact, pragmatic processes may well kick in at an even mere local level if, as suggested by Lieber (2004: 179), some derivational morphemes are semantically underspecified and polysemous. They may even work with linguistic (or perceptual) properties of uttered words other than (and logically prior) to their meaning properties, e.g. phonological or phonetic properties; see Predelli (2010) on the comprehension of malapropisms (e.g. Mrs Malaprop understood as saying that X is a nice arrangement of epithets when she utters 'That's a nice derangement of epitaphs').
} 
instances in which pragmatic inference is essential in establishing the proposition the speaker said and meant (explicitly communicated). ${ }^{15}$

Simons' examples in (1) and (2) are cases of lexical/phrasal narrowing: from 'nest' to 'occupied nest'; from 'buy flowers' to 'buy flowers to give to mother for her birthday'. Having given a Gricean rational reconstruction of how the enrichment can arise within a disjunct or the antecedent of a conditional, she leaves it open whether the resulting communicated proposition is to be construed as 'what is said' or 'what is implicated'. As reviewed in this section, pragmatic inference plays an essential role in establishing the intended sense of words and phrases, hence in determining what the speaker has said. Putting this together with the absence of any motivation for an implicature construal of her cases, as discussed in the previous section, it looks as if the local 'what is said' construal of these cases is correct. In the next section, I outline a particular post-Gricean account of how such pragmatic enrichments can arise as components of the proposition said and meant by the speaker.

\section{Going beyond Gricean rational reconstruction}

The essence of the relevance-theoretic account of utterance interpretation is that hearers are entitled to expect a satisfactory array of contextual implications (and other cognitive effects) in return for the effort of attending to and processing an utterance addressed to them. The pragmatic theory is grounded in a general view of human cognition according to which our cognitive systems are geared toward maximising the cognitive effects they derive from incoming information while being as economical as possible in their expenditure of effort. Given the communicative intention with which utterances are produced, they are special among sources of information in that they convey a presumption of 'optimal relevance', that is, a presumption that the effort of processing them will be adequately rewarded by the cognitive effects they will yield.

This is not the place for a full account of the theory and the foregoing is just a brief and rudimentary characterisation (or reminder) of the framework, but I hope it suffices as an indication of its strong cognitive orientation. ${ }^{16}$ Commensurate with this orientation, the

\footnotetext{
15 Simons' position here is at least partly motivated as a response to the apparent problem of 'Grice's circle' raised by Levinson (2000: 186): 'what is said seems both to determine and to be determined by implicature'. However, this problem has been resolved in several post-Gricean frameworks without resorting to an arbitrary nonpropositionality constraint on the involvement of pragmatic processes in recovering the proposition said and meant. In the next section, I indicate how it is met in the relevance-theoretic framework (see also discussion in Carston 2002). For other solutions to the circularity issue, see Recanati's (2004) distinction between primary and secondary pragmatic processes, and the 'critical pragmatics' approach of Korta \& Perry (2008), who distinguish 'near-side pragmatics' (i.e. contributions to 'official referential content' or what is said) from 'far-side pragmatics' (i.e. implicated contents).

${ }^{16}$ For more detailed article-length accounts of the relevance-theoretic framework and its cognitive underpinnings, see Wilson \& Sperber (2004) or Wearing (2014).
} 
accounts of utterance interpretation it gives are not intended as idealised rational reconstructions of the reasoning by which utterance content could be derived, but as more closely meshed to the actual inferential processes employed by addressees and the ways in which these are constrained by cognitive factors such as different degrees of activation, hence of accessibility, of information in memory. ${ }^{17}$ With this in mind, consider how a relevance-based pragmatic account might explain A's interpretation of B's response to her question in (18):

18. A: What's making noise up in the attic?

B: Oh, there's a nest up there.

Given the expectation of (optimal) relevance that addressees of utterances are entitled to have, A can expect B to provide an answer to her question. But B's answer here is indirect; she implicates that it is birds that are making the noise in the attic. What then is the proposition explicitly communicated (said and meant, in Grice's terms)? Linguistic decoding of the utterance provides the atomic concept NEST which has associated with it a cluster of general world knowledge about nests: that they are a construct, made by birds, of such and such size/shape/composition, that birds lay eggs in them and live in them, etc. Some aspects of this general knowledge about nests will be more activated than others; given the immediately preceding question about the source of noise, information about birds residing in nests and making certain kinds of noise is likely to be highly activated. Such readily accessible assumptions are employed as contextual premises, together with the proposition explicitly expressed, from which contextual implications are inferred, specifically, that it is birds that are making the noise in the attic. But this is not a warranted inference unless the general concept NEST is enriched to something along the lines of NEST OCCUPIED BY BIRDS. Thus, there is a process of 'backwards inference' from the relevance-based implication to the proposition expressed (the truth-conditional content of the utterance) which effects this enrichment. This is an instance of a general pragmatic mechanism of mutual parallel adjustment of (hypothesised) explicature and (hypothesised) implicatures of an utterance, a process which stops when a sound inference which meets the addressee's expectation of relevance is reached. The interpretation of B's utterance derived in this way is roughly the following:

\section{Explicature: THERE IS A NEST* UP IN THE ATTIC}

(where the ad hoc concept NEST* can be paraphrased as 'nest occupied by birds')

\footnotetext{
17 More generally, the approach heeds the findings of evolutionary psychology on the domain-specificity of our cognitive capacities and the bounded nature of our rational functioning (e.g. the use of 'fast and frugal heuristics', as discussed by Gigerenzer \& Selten (2002)). Nonetheless, it probably qualifies as a 'broadly Gricean' account as characterized by Simons: 'any account of pragmatic inference which posits that an interpreter reasons about what the speaker meant and that this reasoning is guided by presumptions of rationality of the speaker is a Gricean account' (p.4).
} 
Implicature: THE NOISE IN THE ATTIC IS MADE BY BIRDS

The embedded cases that are Simons' primary concern would work in much the same way, albeit with additional complications concerning the correct treatment of the logical operators involved. Take one of her disjunction cases:

20. A: What's making noise up in the attic?

B: $\quad$ Either there's a nest up there or some squirrels have moved in.

The implicated answer to A's question is that (B thinks that) the noise in the attic is being made by birds or by squirrels. As in Simons' Gricean derivation, there is some pragmatic inferential work to be done on each of the disjuncts individually, given the relevance-based assumption that each is a potential answer to the question asked, although the speaker does not know which is the correct answer (as the use of the disjunction operator indicates). So the processing of the first disjunct proceeds as just discussed for (18), its relevance lying with the contextual implications it yields, in particular, the implication that nesting birds are a possible source of the noise in the attic. The processing of the second disjunct is similar, its relevance lying with the contextual implication that squirrels are a possible source of the noise in the attic. While the inferences hinging on the first disjunct require pragmatic enrichment of the NEST concept in order to be properly warranted, there is not any obvious comparable concept enrichment in the second disjunct (although, arguably, 'moved in', is completed to 'moved in to the attic'). On this account, the pragmatic enrichment of 'nest' is a component of the proposition explicitly communicated (what Simons nicely calls a 'robust notion of what is said'), whether or not it occurs in a simple sentence or in a more complex structure in which that sentence is embedded. The same would go for all the various cases of lexical/phrasal pragmatics discussed in the previous section. As with Simons' Gricean analyses, the enriching/adjusting of sentence subparts is 'always in the service of rendering the content of the utterance as a whole pragmatically appropriate' (p.23), that is, the inferential processes involved are all in aid of recovering an optimally relevant interpretation of the utterance as a whole.

Recall again Grice's worry: for certain uses of linguistic expressions in simple sentences, an implicature has to be recovered in order to grasp the speaker's meaning (e.g. the metaphorical use of 'cream in X's coffee'; many uses of 'and'-conjunctions), but when they occur in the same sentence embedded under a logical operator what was implicated content in the unembedded case is now a component of what is said (truth-conditional content). This strange inconsistency, which perplexed Grice, disappears on the account proposed here, as the pragmatic enrichment contributes to what is said and meant (truthconditional content) whether the expression at issue occurs embedded or unembedded.

To conclude: Mandy Simons has set out impeccable Gricean accounts of how embedded pragmatic effects arise, so anyone who doubted the ability of the Gricean 
reasoning schema to do this should now be convinced that it can. In this response to her paper, I've suggested that, although this is indeed a job well done, the doubts about its feasibility were misplaced, largely arising from failed attempts to formalise the derivation of scalar implicatures. While Grice himself worried about cases where it seemed that 'implicatures' fall in the scope of logical operators, the basis of his worry, I believe, was the problem they posed for his saying/implicating (semantics/pragmatics) distinction. Finally, I have suggested that it is time to move on from purely rational reconstructions of pragmatic phenomena, whose aim is to reveal the 'logic' of acts of linguistic communication, and to develop accounts that come closer to the cognitive reality of communication and interpretation. $^{18}$

\section{References:}

Carston, R. 2002. Thoughts and Utterances; the Pragmatics of Explicit Communication. Oxford: Blackwell.

Carston, R. 2004. Relevance theory and the saying/implicating distinction. In: L. Horn \& G. Ward (eds.) Handbook of Pragmatics, pp. 633-656. Oxford: Blackwell.

Carston, R. \& Hall, A. 2012. Implicature and explicature. In: H-J. Schmid (ed.) Cognitive Pragmatics [Handbook of Pragmatics, Vol. 4], 47-84. Berlin: de Gruyter Mouton.

Chierchia, G. 2004. Scalar implicatures, polarity phenomena and the syntax/pragmatics interface. In: A. Belletti (ed.) Structures and Beyond: The Cartography of Syntactic Structures, vol. 3, 39-103. Oxford: Oxford University Press.

Clark, E. \& Clark, H. 1979. When nouns surface as verbs. Language 55: 767-811.

Cohen, L.J. 1971. Some remarks on Grice's views about the logical particles of natural language. In Bar-Hillel, Y. (ed.) Pragmatics of Natural Language, 50-68. Dordrecht: Reidel.

Gamut, L. 1991. Logic, Language, and Meaning, Volume 1, Chicago, IL: University of Chicago Press.

Gazdar, G. 1979. Pragmatics: Implicature, Presupposition, and Logical Form. New York: Academic Press.

Geurts, B. 2010. Quantity Implicatures. Cambridge: Cambridge University Press.

${ }^{18}$ Many thanks to Emma Borg and Deirdre Wilson for helpful comments on a pre-final draft of this paper. 
Geurts, R. \& Rubio-Fernandez, P. forthcoming. Pragmatics and processing. Ratio

Gigerenzer, G. \& Selten, R. 2002. Bounded Rationality. Cambridge: MIT Press.

Grice, H. P. 1967/89. Indicative conditionals. Lecture 4 of 'Logic and Conversation', the William James Lectures, Harvard University 1967. In: Grice, H. P. 1989: 58-85.

Grice, H. P. 1975/89. Logic and conversation. In: Cole, P. \& Morgan, J. (eds.) Syntax and Semantics 3: Speech Acts, 41-58. New York: Academic Press. Reprinted in: Grice, H. P. 1989: 22-40.

Grice, H. P. 1987/89. Retrospective epilogue. In: Grice, H. P. 1989: 339-385.

Grice, H.P. 1989. Studies in the Way of Words. Cambridge Mass.: Harvard University Press. Hirschberg, J. 1985. A Theory of Scalar Implicature. PhD thesis, University of Pennsylvania, PA. Published by Garland NY in 1991.

Hobbs, J. 2004. Abduction in natural language understanding. In L. Horn and G. Ward (eds.), Handbook of Pragmatics, pp. 724-741. Oxford: Blackwell.

Hobbs, J. \& Martin, P. 1987. Local pragmatics. Proceedings, International Joint Conference on Artificial Intelligence, pp. 520-523. Milano, Italy, August 1987.

Levinson, S. 1983. Pragmatics. Cambridge: Cambridge University Press.

Levinson, S. 2000. Presumptive Meanings: The Theory of generalized Conversational Implicatures. Cambridge Mass.: MIT Press.

Katz, J.J. 1972. Semantic Theory. New York: Harper and Row.

Korta, K. \& Perry, J. 2008. The pragmatic circle. Synthese 165 (3): 347-357.

Lieber, R. 2004. Morphology and Lexical Semantics. Cambridge: Cambridge University Press.

Nunberg, G. 1979. The non-uniqueness of semantic solutions: polysemy. Linguistics and Philosophy 3: 143-184.

Predelli, S. 2010. Malapropisms and the simple picture of communication. Mind \& Language 25 (3): 329-345.

Recanati, F. 2003. Embedded implicatures. Philosophical Perspectives 17 (1): 299-332.

Recanati, F. 2004. Literal Meaning. Cambridge: Cambridge University Press.

Sauerland, U. 2004. Scalar implicatures in complex sentences. Linguistics and Philosophy 27 (3): 367-391.

Simons, M. 2010. A Gricean view on intrusive implicatures. In: K. Petrus (ed.) Meaning and Analysis: New Essays on H. Paul Grice, pp. 138-169. London: Palgrave Macmillan. 
Stalnaker, R. 1989. On Grandy on Grice on Language. Unpublished paper, MIT. Abstract in Journal of Philosophy LXXXVI, 526-7.

Walker, R. 1975. Conversational implicatures. In: S. Blackburn (ed.) Meaning, Reference and Necessity, 133-181. Cambridge: Cambridge University Press.

Wearing, C. 2014. Relevance theory: pragmatics and cognition. WIREs Cognitive Science. doi: 10.1002/wcs.1331

Wilson, D \& Carston, R. 2007. A unitary approach to lexical pragmatics: relevance, inference and ad hoc concepts. In: N. Burton-Roberts (ed.) Pragmatics, pp. 230-259. London: Palgrave Macmillan.

Wilson, D. \& Sperber, D. 2004. Relevance Theory. In: L. Horn \& G. Ward (eds.) The Handbook of Pragmatics, pp. 607-32. Oxford: Blackwell. 